\title{
Ganglion impar injection approaches and outcomes for coccydynia
}

Sir,

We praise your journal and authors Gonnade et al., on the excellent recent publication titled, "Ganglion impar block in patients with chronic coccydynia."[1] Their study of patients with chronic coccydynia (coccyx pain) showed that ganglion impar injections with local anesthetic block and corticosteroid significantly decreased pain and disability scores even at the maximum length of study follow-up, which was 6-month postinjection.

The authors clearly described injecting the ganglion impar via the sacrococcygeal junction. We would like to point out that other needle approaches can also be done, depending on the patient's anatomy. Specifically, interventional physicians should be aware of alternative approaches via the first $^{[2]}$ or second ${ }^{[3]}$ intracoccygeal joint (between coccygeal vertebral bodies one and two, or between coccygeal vertebral bodies three and fourth, respectively). These approaches have been referred to as being transcoccygeal, intracoccygeal, or coccygeal transdiscal. These newer approaches have some potential advantages. First, since the sacrococcygeal joint is fused in $51 \%$ of humans, ${ }^{[4]}$ these newer approaches provide access through joints that are more likely to be patent. Second, human cadaver studies have shown that the ganglion impar is usually located at the upper coccyx, rather than at the sacrococcygeal joint. ${ }^{[5]}$

We noted that the authors excluded from treatment any patients who had imaging abnormalities that would explain their tailbone pain. This surprised us since our experience 
is that coccydynia patients often respond extremely well to these impar injections, regardless of whether they do or do not have coccygeal imaging abnormalities. We would be very interested in the authors' thoughts on their exclusion criteria.

We hope our comments and the authors' reply will provide even more insights on relieving pain via these injections.

\section{Financial support and sponsorship}

Nil.

\section{Conflicts of interest}

There are no conflicts of interest.

\section{Patrick M Foye, Nourma Sajid, Gerard John D'Onofrio}

Department of Physical Medicine and Rehabilitation, Rutgers New Jersey Medical School, Newark, New Jersey, USA E-mail: doctor.foye@gmail.com

\section{References}

1. Gonnade N, Mehta N, Khera PS, Kumar D, Rajagopal R, Sharma PK, et al. Ganglion impar block in patients with chronic coccydynia. Indian J Radiol Imaging 2017;27:324-8.

2. Foye PM, Buttaci CJ, Stitik TP, Yonclas PP. Successful injection for coccyx pain. Am J Phys Med Rehabil 2006;85:783-4.
3. Foye PM. New approaches to ganglion impar blocks via coccygeal joints. Reg Anesth Pain Med 2007;32:269.

4. Postacchini F, Massobrio M. Idiopathic coccygodynia. Analysis of fifty-one operative cases and a radiographic study of the normal coccyx. J Bone Joint Surg Am 1983;65:1116-24.

5. Oh CS, Chung IH, Ji HJ, Yoon DM. Clinical implications of topographic anatomy on the ganglion impar. Anesthesiology 2004;101:249-50.

This is an open access journal, and articles are distributed under the terms of the Creative Commons Attribution-NonCommercial-ShareAlike 4.0 License, which allows others to remix, tweak, and build upon the work non-commercially, as long as appropriate credit is given and the new creations are licensed under the identical terms.

\begin{tabular}{|l|l|}
\hline \multicolumn{2}{|c|}{ Access this article online } \\
\hline Quick Response Code: & Website: \\
\hline & www.ijri.org \\
\cline { 2 - 3 } & \\
\hline
\end{tabular}

Cite this article as: Foye PM, Sajid N, D'Onofrio GJ. Ganglion impar injection approaches and outcomes for coccydynia. Indian J Radiol Imaging 2018;28:482-3.

○) 2018 Indian Journal of Radiology and Imaging | Published by Wolters Kluwer - Medknow 